\title{
Complications after Endovascular Aneurysm Repair
}

\author{
Geert Maleux, M.D., Ph.D., ${ }^{1}$ Marcel Koolen, M.D., ${ }^{1}$ and Sam Heye, M.D. ${ }^{1}$
}

Endovascular aneurysm repair (EVAR) has become an established technique for the treatment of many infrarenal aortic aneurysms. Although EVAR is obviously less invasive than open surgical repair, it is not free of complications. These can potentially result in severe morbidity or even mortality, stressing the need for an early detection and subsequent treatment. In this review article, the pathophysiology, diagnosis, and treatment of the most common complications of EVAR, with the exception of endoleaks, are described.

KEYWORDS: Aorta, aneurysm, stents, prostheses, complication

\begin{abstract}
Objectives: Upon completion of this article, the reader should be able to identify the common complications seen after endovascular aneursym repair.

Accreditation: Tufts University School of Medicine (TUSM) is accredited by the Accreditation Council for Continuing Medical Education to provide continuing medical education for physicians.

Credit: TUSM designates this educational activity for a maximum of 1 AMA PRA Category 1 Credit $^{\text {TM }}$. Physicians should only claim credit commensurate with the extent of their participation in the activity.
\end{abstract}

Endovascular aortic repair (EVAR) of abdominal aortic aneurysm (AAA) is widely accepted as an effective and less invasive treatment alternative to open surgical AAA repair. ${ }^{1}$ However, this endovascular procedure is not free of complications. These complications, potentially occurring both during and after the EVAR procedure, can be serious, prompting a quick and correct (radiological) diagnosis and subsequent interventional or surgical treatment. Endoleaks are the most common complications after $\mathrm{EVAR}^{2-4}$ and are discussed elsewhere. In this review article, both the clinical and radiological diagnosis and interventional and/or surgical treatment options will be discussed with regard to these non-endoleak-related peri- and postoperative complications.

\section{OVERVIEW OF COMPLICATIONS AFTER ENDOVASCULAR EXCLUSION OF ABDOMINAL AORTIC ANEURYSMS}

Common, non-endoleak-related complications during or after EVAR can be categorized as complications owing to surgical exposure of the cannulated arteries, systemic complications, ischemic complications owing to intentional or inadvertent clot embolization or covering of an aortic side branch, stenosis or occlusion of a

\footnotetext{
${ }^{1}$ Department of Radiology, University Hospitals Leuven, Leuven, Belgium.

Address for correspondence and reprint requests: Geert Maleux, M.D., Ph.D., Department of Radiology, University Hospitals Leuven, Herestraat 49, B-3000 Leuven, Belgium (e-mail: geert.maleux@uz. kuleuven.ac.be).
}

Aortic Stent Grafts; Guest Editor, S. William Stavropoulos, M.D. Semin Intervent Radiol 2009;26:3-9. Copyright (C) 2009 by Thieme Medical Publishers, Inc., 333 Seventh Avenue, New York, NY 10001, USA. Tel: +1(212) 584-4662.

DOI 10.1055/s-0029-1208377. ISSN 0739-9529. 
stent-graft limb, and infection complications of the stent graft and excluded aneurysmal sac.

\section{Surgical Complications}

\section{LOCAL WOUND COMPLICATIONS IN THE GROIN}

Local wound complications include groin hematoma, infection, or lymphocele, and the incidence is 1 to $10 \%{ }^{3}$ Although clinical surveillance with or without medical treatment or surgical repair are mostly enough for definitive treatment, ultrasound (US) or computed tomography $(\mathrm{CT})$ evaluation can be needed to evaluate the extent of the lesion.

\section{ACCESS ARTERY INJURY}

Arterial thrombosis, dissection, or pseudoaneurysm formation can occur in up to 3\% of EVAR procedures. Besides correct surgical skills, a thorough preoperative US or CT evaluation of the common femoral and iliac arteries with special attention to access vessel diameter, tortuosity, and degree of calcification is mandatory. The stiff and large-catheter system of the stent graft (commonly between 20- and 24-French) potentially cannot be introduced within the aortic aneurysm, especially in the presence of small and heavily calcified iliofemoral access arteries, resulting in abortion of the EVAR procedure or conversion to an iliac conduit. Finally, the introduction of the large-catheter system can induce vessel wall dissection or even perforation. In case of a postsurgical groin pseudoaneurysm (Fig. 1), US-guided thrombin injection is not always successful as the pseudoaneurysmal neck can be too large, making surgical repair the only definitive treatment option.

\section{Contrast Nephropathy}

Correct positioning and deployment of the stent graft strictly needs high-quality fluoroscopy and digital sub-

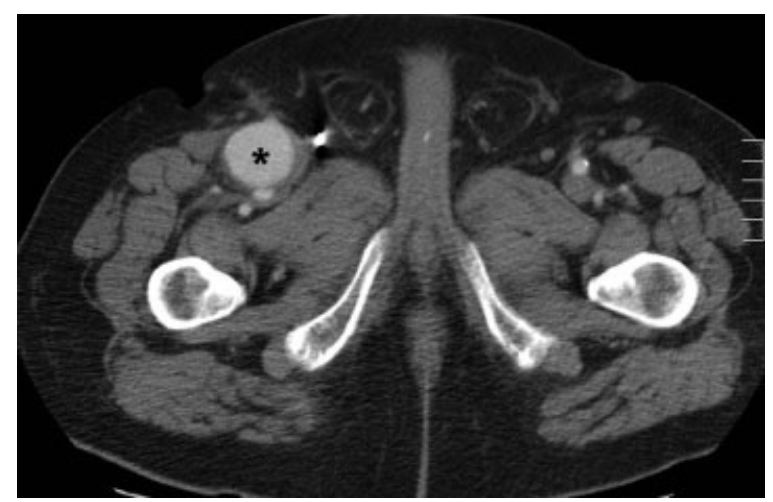

Figure 1 Computed tomography scan 1 week after stent grafting shows large pseudoaneurysm in the right groin (asterisk). traction angiography imaging using injection of iodinized contrast medium. Commonly, an average amount of 50 to $100 \mathrm{~mL}$ of dye is needed for an EVAR procedure. Contrast-induced nephropathy, resulting in acute renal failure, occurs in $6.7 \%$ of cases, according to a nationwide survey by Wald et al. ${ }^{5}$ To avoid these contrast-induced renal complications, carbon dioxide $\left(\mathrm{CO}_{2}\right)$ can be used as an alternative contrast agent. ${ }^{6,7}$ Additionally, $\mathrm{CO}_{2}$ can be injected through the stentgraft delivery catheter, making the placement of a pigtail catheter in the aorta unnecessary. ${ }^{8}$

\section{Ischemic Complications Immediately after EVAR}

Ischemic complications that occur immediately after EVAR can be due to clot formation or clot embolization into aortic side branches and include colonic, renal, and pelvic ischemia. Adversely, misplacement of the stent graft, thereby partially or completely covering an aortic or iliac side branch, can result in renal or pelvic ischemia.

\section{COLONIC ISCHEMIA}

Bowel ischemia occurs in 1 to $3 \%$ of cases after open aortic aneurysm repair, and the incidence seems to be in the same as for EVAR. ${ }^{9} 10$ Postoperative bowel ischemia after aortic aneurysm repair still remains a serious complication with a mortality rate of $50 \%$ within 1 month. ${ }^{9}$ However, the pathophysiological mechanism of colonic ischemia in open versus endovascular repair is most probably different. Whereas interruption of the inferior mesenteric or iliac arteries has been suggested to be the cause of bowel ischemia in open procedures, the same mechanism does not seem to be important for EVAR. Zhang et $\mathrm{al}^{11}$ presume that the presence of thrombotic deposits and atheroma in the suprarenal aorta may be responsible for major bowel ischemia in EVAR procedures. These thrombotic and atheromatous deposits can be dislodged while the proximal part of the endograft is being positioned and deployed just below the renal arteries or when the proximal part of the endograft is balloon-dilated. These maneuvers can induce upstream flushing of mural clot material or atherosclerotic debris into the superior mesenteric artery. These microemboli may also migrate into the renal, inferior mesenteric, internal iliac, and lower-limb circulation resulting in segmental, skipped, or patchy ischemia of the embolized areas. This mechanism of microemboli embolization also explains why bowel ischemia after EVAR mostly presents as multifocal patchy ischemia. This type of bowel ischemia is not seen after open repair, most probably because suprarenal aortic and ostial inferior mesenteric arterial clamping during open repair makes distal microembolization unlikely. Finally, these observations also stress the importance of careful preoperative analysis of the proximal aneurysmal neck to identify 


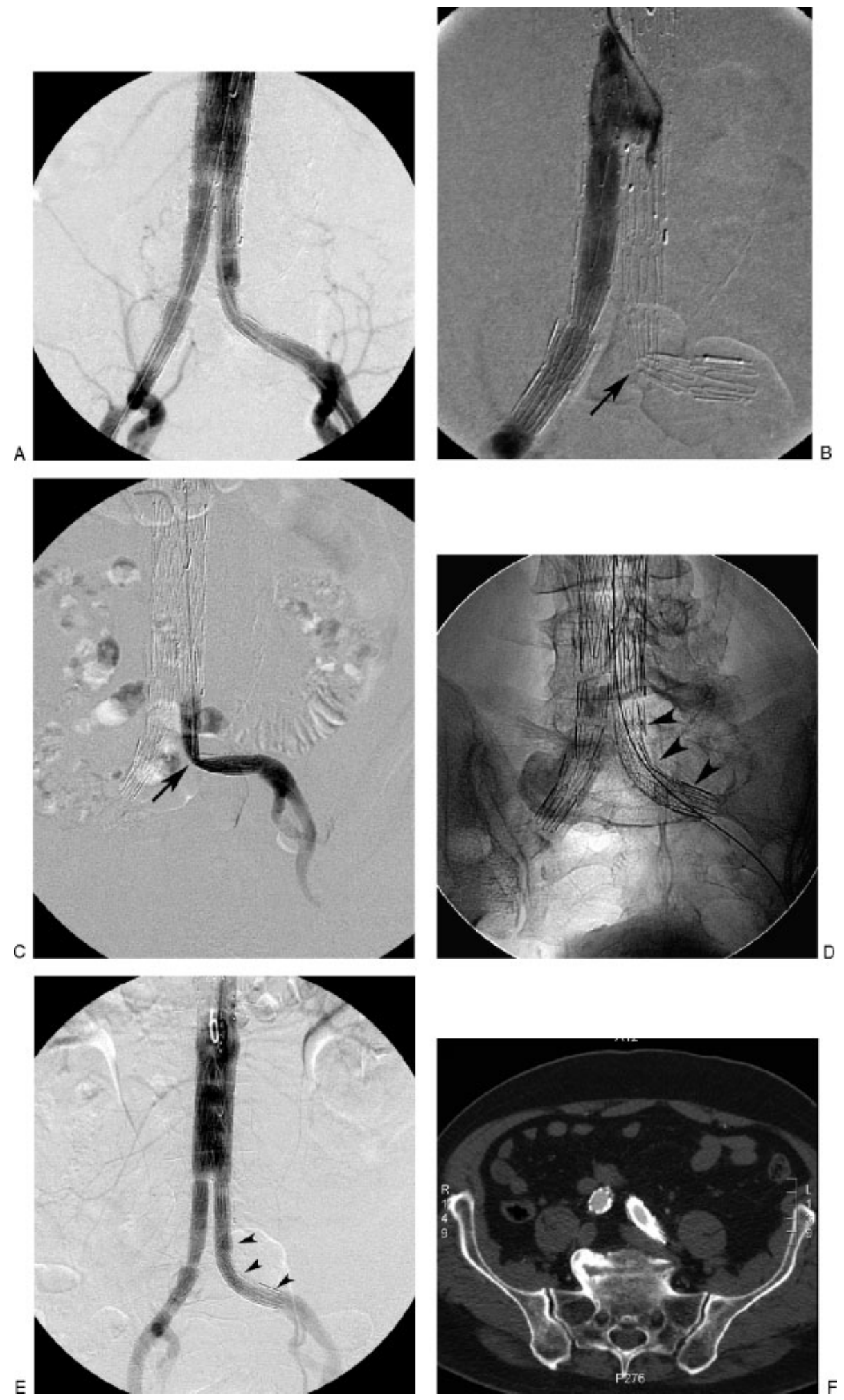

Figure 2 Completion angiography $(\mathrm{A})$ after implantation of a fenestrated stent graft (Zenith; Cook Medical). No kinking or residual stenosis was noted. One week later, the patient presented with acute left lower-limb ischemia. Angiography by brachial approach (B) confirmed left limb occlusion associated with important kinking of the left stent-graft limb (arrow). After 24 hours of in situ thrombolysis, the left limb was declotted (C). Note the residual stenosis (arrow) owing to limb kinking between two Z-stents. An additional self-expanding stent (Wallstent, Boston Scientific) (arrowheads) was placed to treat the kinking (D, E). Control computed tomography scan 2 years after successful thrombolysis shows a normally patent left stentgraft limb with additional Wallstent (F). 
thrombus or atheroma, making these patients poor candidates for EVAR.

\section{SPINAL CORD ISCHEMIA}

Spinal cord ischemia after EVAR for AAA is very rare, and the EUROSTAR database found an incidence of $0.21 \%$ in 2862 patients. ${ }^{12}$ The mechanism is not completely understood, but atheromatous embolization and interruption of collateral circulation from lumbar and internal iliac arteries together with a variable anatomy of the artery of Adamkiewicz seem to be the most contributing factors. The treatment is the same as for paraplegia after thoracoabdominal EVAR or open repair and consists in cerebrospinal fluid drainage ${ }^{13-16}$ and, if indicated, recanalization of occluded collateral arteries like the internal iliac artery. ${ }^{17}$

\section{RENAL ARTERY OCCLUSION (STENTING AND RETRIEVAL OF THE STENT GRAFT)}

Inadvertent stent-graft placement with partial or total coverage of one or both renal arteries occurs in less than $5 \%$ of cases ${ }^{18}$ and is potentially associated with the lack of high-quality imaging technology for guiding the EVAR procedure and a learning curve of the endovascular team. In their early experience with aortic stent grafting, Kalliafas et $\mathrm{a}^{18}$ described renal artery occlusion in 5 of 204 patients, resulting in renal failure with chronic hemodialysis need in two of them. If misplacement is detected during EVAR, then an attempt can be made, using a pull-down maneuver with an inflated angioplasty balloon or by tugging caudally on a guide wire placed across the endograft bifurcation and exteriorized from both femoral arteries. Using this technique, Görich et $\mathrm{al}^{19}$ could move the stent graft from 5 to
$27 \mathrm{~mm}$ more distally. Importantly, these authors did not perform this procedure on stent grafts with barbs at the proximal part of the suprarenal stent.

Finally, in case of partial coverage of one renal artery, stent placement in the renal artery with slight protrusion of the stent over the proximal part of the stent graft into the aorta can also solve the problem. ${ }^{20}$

\section{Early and Late Limb Occlusion after EVAR}

Limb thrombosis in abdominal aortic stent grafts is a known complication, especially in unsupported endografts, in which it can occur in as many as $40 \%$ of cases. ${ }^{21,22}$ The underlying mechanism is most frequently limb kinking of the unsupported endograft limb. Second-generation supported stent grafts perform better than unsupported endografts with regard to avoidance of limb thrombosis, and these secondgeneration stent grafts are all associated with varying rates of limb occlusion ranging between $0 \%$ and $5 \% .^{23}$ Most of the thrombotic events occur within the first 2 months after EVAR, and the underlying causes of limb thrombosis are stent-graft kinking (Fig. 2) and extension of the small-diameter stent graft into the external iliac artery. ${ }^{24,25}$ Recently, it has been demonstrated that limb occlusion can also occur long after EVAR. The pathophysiological mechanism of late (after 4 to 5 years of follow-up) limb occlusion can be migration and dislocation of an endograft component causing major turbulence of hemodynamics and eventually limb or entire stent-graft thrombosis. ${ }^{23}$ Treatment of limb occlusion includes various surgical and endovascular revascularization techniques; the best treatment option depends on the patient's general
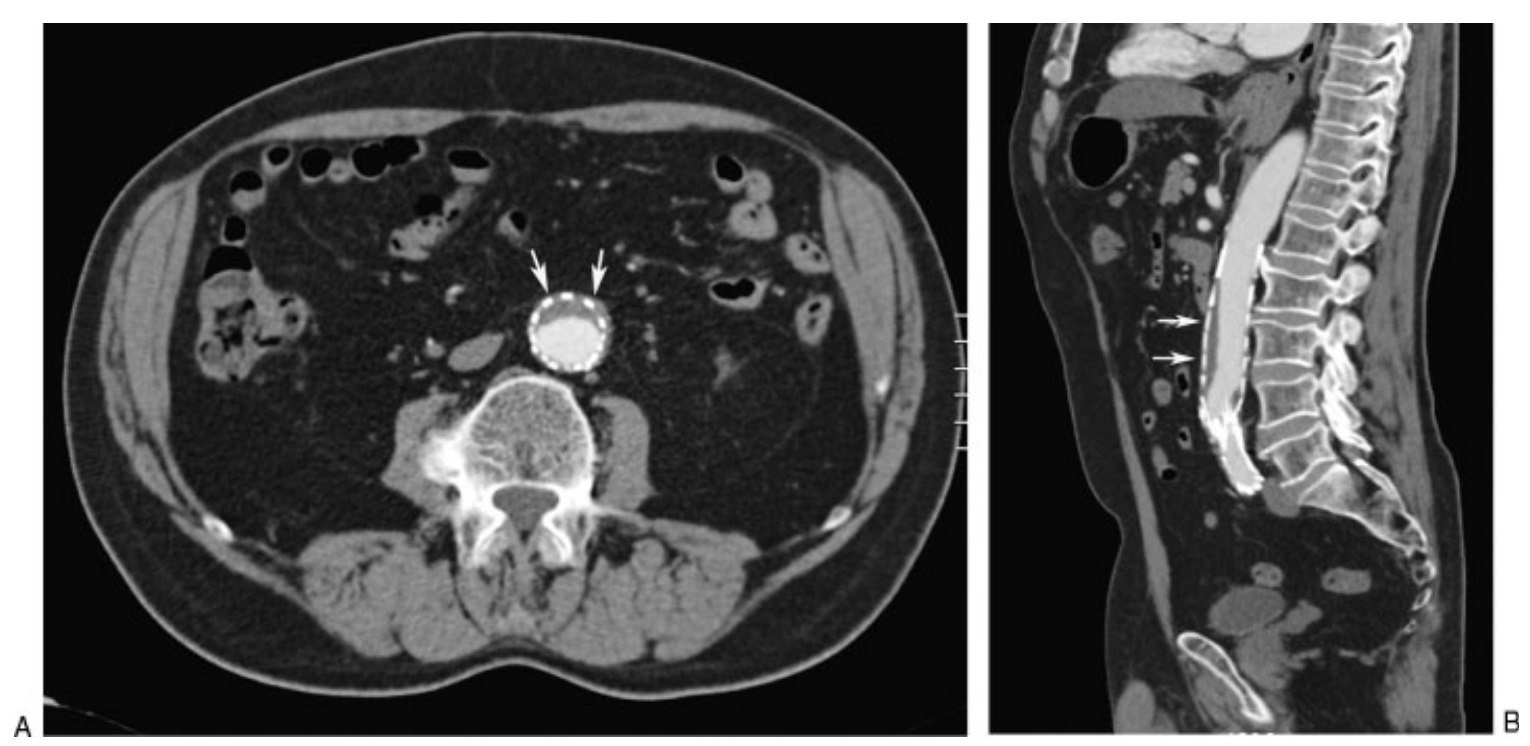

Figure 3 Computed tomography scan with axial (A) and sagittal (B) reconstruction 2 years after Zenith stent-graft implantation demonstrating semicircular mural deposits (arrows) within the body of the endoprosthesis. The patient is completely asymptomatic. 

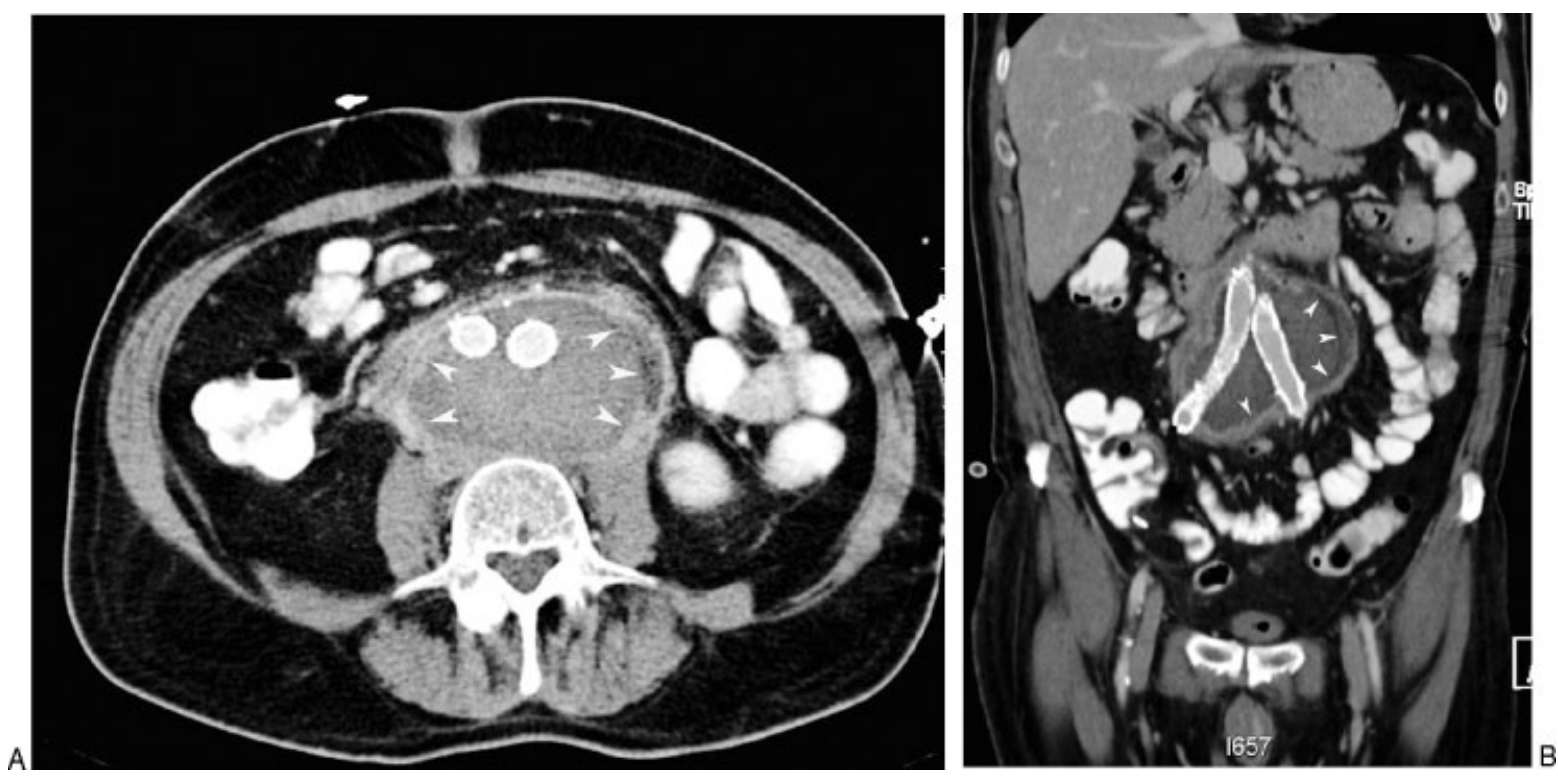

Figure 4 Computed tomography scan showing abdominal aortic aneurysm excluded by the stent graft, with axial (A) and coronal (B) reconstructions, 1 month after stent grafting, in a patient presenting with fever, general malaise, and back pain. The rim of the aneurysmal sac (arrowheads) is contrast enhanced, suggesting sac infection.

status as well as on local anatomic changes of the stent graft and excluded aneurysm.

In contrast to limb thrombosis after EVAR, incidentally found mural thrombotic deposits are much more frequent in both first- $(20 \%)$ and second-generation (17 to $33 \%$ ) supported endografts. ${ }^{26}$ This circumferential layer of thrombotic material (Fig. 3) is observed more in Zenith stent grafts (Cook Medical, Bloomington, IN) than in Excluder stent grafts (W.L. Gore and Associates, Flagstaff, AZ), but they are clinically silent and are not associated with potential stent-graft thrombosis or distal embolization. Additionally, there is no difference in survival among patients presenting with mural deposits in their endograft compared with patients without this thrombotic layer. Based on these observations, additional treatment in the form of relining the endograft with another endograft or administering any type of anticoagulant therapy cannot be recommended to these patients.

\section{Infection Complications after EVAR}

The incidence of aortic stent-graft infection is 0.5 to $1 \%$, and untreated stent-graft infection can result in generalized sepsis and death. ${ }^{27}$ There are multiple causes of endograft infection. Endograft contamination during EVAR procedure seems to be the source of early infection. Secondary infection from a remote source is another pathophysiological mechanism of graft contamination: van den Berg et $\mathrm{al}^{28}$ reported a stent-graft infection following septic complication of a kidney stone 1 year after EVAR procedure. Another case of stent-graft infection after EVAR is shown in Fig. 4. In this case, the patient underwent an appendectomy for appendicitis and periappendicular abscess formation 1 month prior to EVAR. The cause of stent-graft infection can be periprocedural contamination, but also contamination from the appendicitis-induced peritonitis. A third cause of infection is an aortoenteric fistula (Fig. 5). Multiple mechanisms of aortoenteric fistula creation are already described and include stent-graft migration, erosion of the aorta and duodenum by embolization coils, fabric rupture, inflammatory nature of the aneurysm, and bacterial aortitis with chronic duodenal erosion. ${ }^{29-32}$

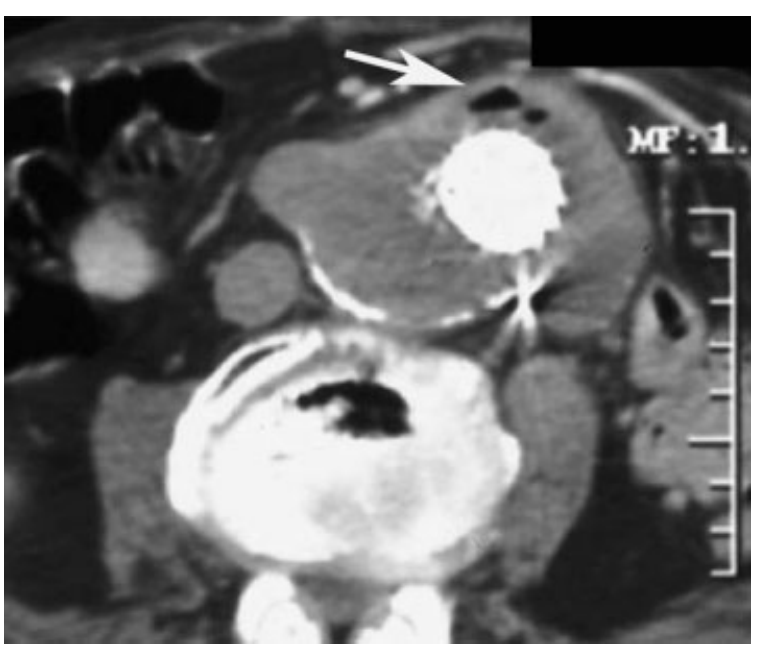

Figure 5 Another radiological presentation of aneurysmal sac infection: air bubbles (arrow) in the aneurysmal sac, close to the adjacent duodenum. 


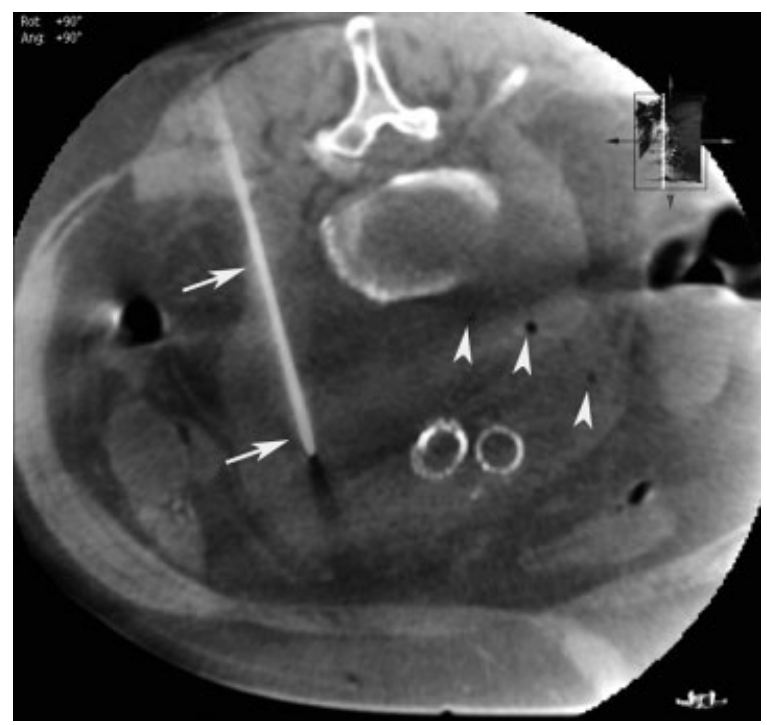

Figure 6 Computed tomography-guided (X-per CT, Philips, Best, The Netherlands) puncture (arrows) of the infected and excluded aneurysmal sac confirms Escherichia coli contamination of the clot. Note also the air bubbles within the clot (arrowheads).

Diagnosis of endograft infection is based on clinical and radiological findings; leukocytosis, fever, and back pain are typical clinical signs, and contrastenhanced CT scan will show a fluid collection around the rim of the aneurysmal sac. Air bubbles can be seen within the aneurysmal sac. ${ }^{33,34}$ An additional puncture of the collection or sac for microbiological analysis gives the definitive diagnosis (Fig. 6).

After intravenous administration of antibiotics, treatment is always resection of the endograft and aneurismal sac, followed by extra-anatomic bypass or in situ venous bypass.

\section{CONCLUSION}

Nonendoleak complications are relatively infrequent during or after EVAR-procedures for AAA. However, thorough knowledge of the potential complications, early (radiological) diagnosis, and appropriate treatment are mandatory to reduce morbidity or even mortality due to these complications.

\section{REFERENCES}

1. Blankensteijn JD, de Jong SE, Prinssen M, et al. Dutch Randomized Endovascular Aneurysm Management (DREAM) Trial Group. Two-year outcomes after conventional or endovascular repair of abdominal aortic aneurysms. N Engl J Med 2005;352:2398-2405

2. Katzen BT, MacLean AA. Complications of endovascular repair of abdominal aortic aneurysms: a review. Cardiovasc Intervent Radiol 2006;29:935-946
3. Liaw JV, Clark M, Gibbs R, Jenkins M, Cheshire N, Hamady M. Update: complications and management of infrarenal EVAR. Eur J Radiol 2008; July 8 (Epub ahead of print)

4. Golzarian J, Struyven J. Imaging of complications after endoluminal treatment of abdominal aortic aneurysms. Eur Radiol 2001;11:2244-2251

5. Wald R, Waikar SS, Liangos O, Pereira BJ, Chertow GM, Jaber BL. Acute renal failure after endovascular vs open repair of abdominal aortic aneurysm. J Vasc Surg 2006;43:460-466

6. Gahlen J, Hansmann J, Schumacher H, Seelos R, Richter GM, Allenberg JR. Carbon dioxide digital subtraction angiography for endovascular grafting in high-risk patients with infrarenal abdominal aortic aneurysms. J Vasc Surg 2001; 33:646-649

7. Chao A, Major K, Kumar SR, et al. Carbon dioxide digital subtraction angiography-assisted endovascular aortic aneurysm repair in the azotemic patient. J Vasc Surg 2007;45:451458

8. Criado E, Kabbani L, Cho K. Catheter-less angiography for endovascular aortic aneurysm repair: a new application of carbon dioxide as a contrast agent. J Vasc Surg 2008;48:527534

9. Becquemin JP, Majewski M, Fermani N, et al. Colon ischemia following abdominal aortic aneurysm repair in the era of endovascular abdominal aortic repair. J Vasc Surg 2008; 47:258-263

10. Perry RJ, Martin MJ, Eckert MJ, Sohn VY, Steele SR. Colonic ischemia complicating open versus endovascular abdominal aortic aneurysm repair. J Vasc Surg 2008;48:272277

11. Zhang WW, Kulaylat MN, Anain PM, et al. Embolization as cause of bowel ischemia after endovascular abdominal aortic aneurysm repair. J Vasc Surg 2004;40:867-872

12. Berg P, Kaufmann D, van Marrewijk CJ, Buth J. Spinal cord ischaemia after stent-graft treatment for infra-renal abdominal aortic aneurysms. Analysis of the Eurostar database. Eur J Vasc Endovasc Surg 2001;22:342-347

13. Fortes DL, Atkins BZ, Chiou AC. Delayed paraplegia following intrarenal abdominal aortic endograft placement: case report and literature review. Vascular 2004;12:130-135

14. Reid JA, Mole DJ, Johnston LC, Lee B. Delayed paraplegia after endovascular repair of abdominal aortic aneurysm. J Vasc Surg 2003;37:1322-1323

15. Garcia ND, Tehrani H, Morasch M, Pearce W, Matsumura J. Spinal cord ischemia following endovascular repair of an infrarenal aortic aneurysm. Ann Vasc Surg 2002;16:509-512

16. Rockman CB, Riles TS, Landis R. Lower extremity paraparesis or paraplegia subsequent to endovascular management of abdominal aortic aneurysms. J Vasc Surg 2001;33:178-180

17. Bajwa A, Davis M, Moawad M, Taylor PR. Paraplegia following elective endovascular repair of abdominal aortic aneurysm: reversal with cerebrospinal fluid drainage. Eur J Vasc Endovasc Surg 2008;35:46-48

18. Kalliafas S, Albertini JN, Macierewicz J, et al. Incidence and treatment of intraoperative technical problems during endovascular repair of complex abdominal aortic aneurysms. J Vasc Surg 2000;31:1185-1192

19. Görich J, Krämer S, Rilinger N, et al. Malpositioned or dislocated aortic endoprostheses: repositioning using percutaneous pull-down maneuvers. J Endovasc Ther 2000;7:123131

20. van Dijk LC, van Sambeek MR, Cademartiri F, Pattynama PM. Partial blockage of the renal artery ostium after 
stent-graft placement: detection and treatment. J Endovasc Ther 2003;10:684

21. Fairman RM, Baum RA, Carpenter JP, et al. The Phase II EVT Investigators.. Limb interventions in patients undergoing treatment with an unsupported bifurcated aortic endograft system: a review of the Phase II EVT Trial. J Vasc Surg 2002;36:118-126

22. Amesur NB, Zajko AB, Orons PD, Makaroun MS. Endovascular treatment of iliac limb stenoses or occlusions in 31 patients treated with the Ancure graft. J Vasc Interv Radiol 2000;11:421-428

23. Maleux G, Koolen M, Heye S, Nevelsteen A. Limb occlusion after endovascular repair of abdominal aortic aneurysms with supported endografts. J Vasc Interv Radiol 2008;19:1409-1412

24. Maldonado TS, Rockman CB, Riles E, et al. Ischemic complications after endovascular abdominal aortic aneurysm repair. J Vasc Surg 2004;40:703-710

25. Carroccio A, Faries PL, Morrissey NJ, et al. Predicting iliac limb occlusions after bifurcated aortic stent grafting: anatomic and device-related causes. J Vasc Surg 2002;36: 679-684

26. Maleux G, Koolen M, Heye S, Heremans B, Nevelsteen A. Mural thrombotic deposits in abdominal aortic endografts are common and do not require additional treatment at shortterm and midterm follow-up. J Vasc Interv Radiol 2008;19: $1558-1562$
27. Sharif MA, Lee B, Lau BB, et al. Prosthetic stent graft infection after endovascular abdominal aortic aneurysm repair. J Vasc Surg 2007;46:442-448

28. van den Berg HR, Leijdekkers VJ, Vahl A. Aortic stent-graft infection following septic complications of a kidney stone. Cardiovasc Intervent Radiol 2006;29:443-445

29. Saratzis N, Saratzis A, Melas N, Ktenidis K, Kiskinis D. Aortoduodenal fistulas after endovascular stent-graft repair of abdominal aortic aneurysm: single-center experience and review of the literature. J Endovasc Ther 2008;15:441-448

30. Bergqvist D, Björck M, Nyman R. Secondary aortoenteric fistula after endovascular aortic interventions: a systematic literature review. J Vasc Interv Radiol 2008;19:163-165

31. Parra JR, Lee C, Hodgson KJ, Perler B. Endograft infection leading to rupture of aortic aneurysm. J Vasc Surg 2004;39: 676-679

32. Baker M, Uflacker R, Robison JG. Stent graft infection after abdominal aortic aneurysm repair: a case report. J Vasc Surg 2002;36:180-183

33. Mita T, Arita T, Matsunaga N, et al. Complications of endovascular repair for thoracic and abdominal aortic aneurysm: an imaging spectrum. Radiographics 2000;20: 1263-1278

34. Orton DF, LeVeen RF, Saigh JA, et al. Aortic prosthetic graft infections: radiologic manifestations and implications for management. Radiographics 2000;20:977-993 